\title{
An Acoustic Study of Welsh and Slavonic Rhotics
}

\author{
Sylwester Faworski \& Sabine Asmus
}

\section{Introduction}

The word rhotics, or, informally, $r$-sounds, is an umbrella term that refers to a natural class of speech segments whose members share a number of phonological properties despite varying significantly with respect to place and manner of articulation. Common r-sounds found in the world's languages include dental/alveolar and uvular trills $[\mathrm{r} \mathrm{R}]$, dental/alveolar taps $[\mathrm{r}]$, voiced and voiceless uvular fricatives [в $\chi$ ], alveolar approximants $[\mathrm{I}]$ and their retroflex variants [.]. So diverse is the class of rhotics that Ladefoged \& Maddieson (1996: 215) conclude that the only feature that $r$-sounds have in common is their representation of numerous variations of the base grapheme $<r>$ in those languages that use the Latin alphabet. For instance, $<\check{r}>$ represents the fricated trill of Czech, $<$ hr $>$ stands for the fortis trill [r] in Irish orthography, ${ }^{1}$ while the digraph $<\mathrm{rz}>$ is a Polish spelling convention to represent the sound [3] that has evolved from the palatalised trill $/ \mathrm{r}^{\mathrm{j}}$ /

The most intriguing facts about rhotics is that markedly different sounds share a number of significant phonological properties. For instance, the manner of articulation of an r-sound does not seem to affect its phonotactic properties. Rhotics tend to have several distinct articulatory variants, yet they do not occur in complementary distribution. Sounds belonging to this natural class, irrespective of their articulation, pose a challenge to the speaker as they are usually among the last speech sounds mastered by children in the process of language acquisition (Vihmann 1996). The inherent difficulty of rhotics also makes them particularly susceptible to phonetic change, as evidenced by historical linguists (e.g. Carlton 1990; Rospond 1973). In addition, Labov's (1966) classic study demonstrated that the frequency with which the rhotic sound occurs in the speech of New Yorkers can be related to the social group the speakers come from. In other words, the sound can be thought of as a social marker, as is potentially true for any sound.

This paper examines samples of Welsh speech acoustically with a view to determining the extent of allophonic variation exhibited by the

1. For the use of this term, see Asmus \& Grawunder (2017, fc.). 
spirantised trill $/ \mathrm{r}_{0}^{\mathrm{h}} / .^{2}$ Being a sound of extraordinary complexity, $/ \mathrm{r}^{\mathrm{h}} /$ is probably more susceptible to phonetic change than plain trills. It further follows that, in connected speech, this segment is likely to be replaced with various sounds that represent a lesser degree of articulatory complexity. Since the informants come from different parts of Wales, an attempt is made to establish whether the substitutions made by speakers of North Welsh differ from those produced by southerners. Finally, the Welsh spirantised $/ \mathrm{r}^{\mathrm{h}} /$ is compared to the Czech fricated $/ \mathrm{r} /$ and the Russian palatalised $/ \mathrm{r}^{\mathrm{j}} /$ with respect to their susceptibility to phonetic reduction.

The paper is structured as follows. Section 1 provides general information regarding the natural class of rhotics. Section 2 presents an outline of the phonology of rhotics from a cross-linguistic perspective. Section 3 is concerned with the acoustic properties of trills and explains why they are so prone to reduction. Section 4 introduces the data collection methods of the current study, which include a phonetic experiment involving 23 native speakers of Welsh and the analysis of recordings obtained from audiobooks for the Slavic languages. The remaining part of this section is devoted to the presentation of the findings. This is followed by Section 5 containing concluding remarks.

\section{The natural class of rhotics}

As indicated above, due to the remarkable articulatory diversity of rhotics, finding a single acoustic feature that they have in common poses a challenge. A lowered value of the third formant (F3) appears to be the only acoustic property shared by several types of rhotics, but uvular r-sounds have a relatively high third formant and so do dental ones (Lindau 1985: 165). Having examined various types of rhotics, Lindau (1985:166) states that "there is no physical property that constitutes the essence of all rhotics".

Although a satisfactory definition of rhotics has not been provided yet (Maddieson 1984; Lindau 1985; Ladefoged \& Maddieson 1996; Wiese 2001, 2011), there is a body of statistical data that allows linguists to make generalisations as to which sound can be regarded as the prototypical rhotic. The list of general statements on rhotics shown in (1) is the result of an analysis of r-sounds found in a representative sample of 316 languages performed by Maddieson (1984: 82).

2. Considering that Welsh is an aspiration language and following others, e.g. Broderick (2016), Asmus \& Grawunder (2017) use the IPA symbol [r] for this spirantised rhotic in order to differentiate it from the aspirated allophone $/ \mathrm{r}^{(\mathrm{h})} / \mathrm{of} / \mathrm{r} /$, which is strong in the Bala Lake District. The transcription is debated and Thomas (2000) uses the sequence [hr] to represent the spirantised trill. Throughout this work, however, we use $/ \mathrm{r}^{\mathrm{h}} /$ as suggested by Hannahs (2012: 43). 
(1)
a. An r-sound is likely to be voiced.
$308 / 316$
$97.5 \%$
b. An r-sound is likely to be dental or alveolar.
$273 / 316$
$86.4 \%$
c. An r-sound is likely to be interrupted.
$244 / 282$
$86.5 \%$
d. A retroflex r-sound is likely to be a continuant.
$20 / 38$
$52.6 \%$
e. An approximant $r$-sound is likely to be retroflex.
$15 / 28$
$53.6 \%$
f. A fricative r-sound is likely to be retroflex.
$5 / 10$
$50.0 \%$

The statements in (1) point to the conclusion that the prototypical rhotic is voiced, dental/alveolar, interrupted ${ }^{3}$ and continuant. The apical trill $[\mathrm{r}]$ is the only sound that meets these criteria (Lindau 1985). However, the articulation of [r] requires a great deal of precision (Solé 2002; Ladefoged \& Maddieson 1996; Żygis 2005; Wiese 2011) Therefore, it is liable to phonetic change.

\subsection{An outline of the phonology of rhotics}

It is paradoxical that sounds as diverse as rhotics exhibit striking similarities in the domain of phonology. Wiese $(2003,2011)$ provides a list of generalisations suggesting that rhotics do constitute a natural class. These include phonotactic properties, syllabicity, synchronic and diachronic alternations and phonological consequences of such alternations (see also Hall 1997; Walsh Dickey 1997).

As far as the first generalisation is concerned, rhotics tend to occupy privileged, vowel-adjacent positions within the syllable. It follows that they typically occur in syllable-initial, intervocalic and syllable-final position. In those languages that allow for consonant clusters, rhotics usually follow the $\mathrm{CrVrC}$ sound pattern, where the onset and coda $\mathrm{C}$ slots can be occupied by more than one consonant.

Another phonological feature characteristic of rhotics is that, in many languages, they have a syllabic variant. For instance, non-vowel-adjacent rhotics of Czech, Croatian and American English have syllabic variants, as in $\mathrm{Cz}$ krtek 'mole', Cr krk 'neck', AE runner, pronounced ['rın. I]. On the other hand, in some other languages, e.g. Polish, Russian and Ukrainian, rhotics found in such sound combinations are classified as obstruentised

3. In Maddieson's (1984) terminology, both trills and taps/flaps are referred to as "interrupted" as they consist of, at least, one complete closure. Obviously, the other manners of articulation are labelled "uninterrupted". 
rhotics (Gussmann 2007; Jaworski 2014). R-sounds of this type are found, for instance, in P krtań 'larynx' [krtap], R pma [rta] 'mouth' (gen. sing.) and $\mathrm{U}$ pmymi rtut $\left.^{\mathrm{j}} \mathrm{i}\right]$ 'mercury'.

As aforementioned, synchronically and diachronically, rhotics exhibit a very strong tendency towards phonetic change. Lindau (1985) argues that the usual pattern of change involves a gradual decrease in the degree of constriction, whose final outcome is the deletion of a rhotic segment as illustrated graphically in Figure 1. Although this graph covers many of the attested changes, it does not make any reference to the $/ \mathrm{r} />/ \mathrm{R} /$ change that has taken place in a number of European languages, e.g. French, Danish and Swedish (Demolin 2001).

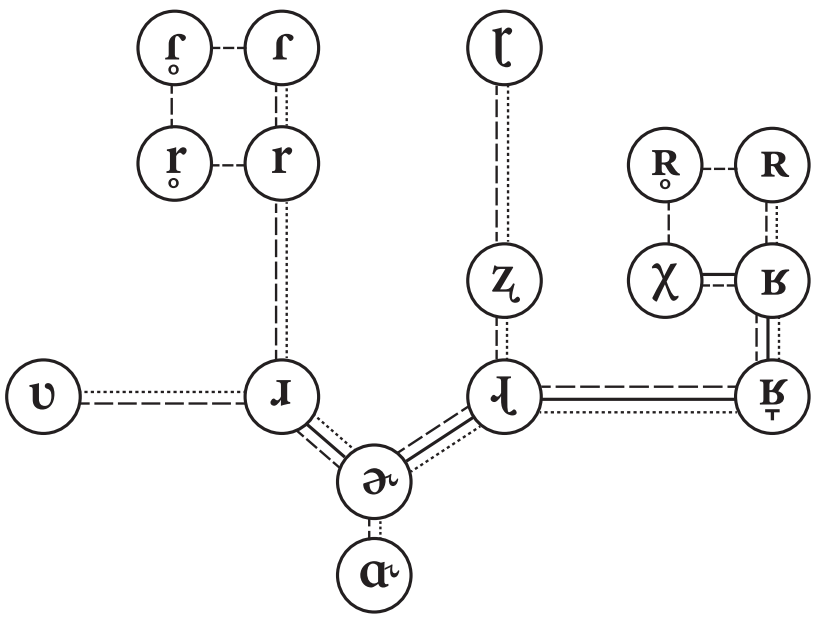

Figure 1. Associations between various types of rhotics (after Lindau 1985).

Relatively common phonological changes, most of which are represented in the graph, include the following: (i) neutralisation of the $/ \mathrm{r} /-/ \mathrm{r} /$ distinction observed in the speech of Spanish-speaking Filipinos (Lipski 1987a: 32) or in the Spanish of Equatorial Guinea (Lipski 1987b:11); (ii) neutralisation of the $/ \mathrm{r} /-/ \mathrm{r}^{\mathrm{j}} /$ contrast that affected the sound systems of several Slavonic languages (Żygis 2005; Kavitskaya et al. 2009); (iii) uvularisation, or the $/ \mathrm{r} />/ \mathrm{R} /$ change, that occurred in a number of European languages, e.g. French, Swedish, Danish and German (Demolin 2001); (iv) lateralisation, i.e. replacing rhotics with laterals, which occurs regularly in many varieties of Spanish, e.g. in harto 'full' pronounced [alto] or mar 'sea' pronounced [mal] (Hualde 2005:188); (v) metathesis, i.e. reordering of segments, which 
affected the sound systems of all Slavonic languages, e.g. the Proto-Slavonic word *korva 'cow' was rendered kráva in Slovene and Czech, krowa in Polish and Lower Sorbian, krava in Slovak and kruva in Upper Sorbian (Carlton 1990).

The alternations observed both synchronically and diachronically do not seem to affect the phonotactic properties of rhotics (Wiese 2003:12). In other words, in the theoretical CrVrC syllable, the rhotic slots can be occupied by rhotic segments ranging from trills to approximants. The statement remains true even if an apical rhotic is replaced with a velar one. This fact can be easily confirmed by listening to Poles who have a speech impediment and cannot pronounce an apical trill. In their speech, /r/ is usually realised phonetically either as the velar fricative [ $\mathrm{B}]$ or the postalveolar approximant $[\mathrm{x}]$.

\section{Trills}

A trill is produced when the active articulator is set in vibration by the airstream in the oral cavity. Trills are the only speech sounds for which the articulation of the movements of the active articulator are not controlled by any muscular action (Ladefoged \& Maddieson 1996:217; Solé 2002). Instead, the vibration results from the aerodynamic conditions created by an airstream passing through the aperture between the active and passive organ. When the organs separate, a certain volume of air flows through the aperture and, consequently, the pressure behind the place of articulation drops dramatically allowing the active articulator to spring back to its former position producing another closure. ${ }^{4}$ In many languages, e.g. Spanish, Italian, a typical trill consists of two or three closures, but the number of cycles depends on speaking style, on the position a trill occupies within the syllable and, also, on the place of articulation. According to Solé (2002:669), the frequency of vibration of a voiced apical trill is in the range of $26-29 \mathrm{~Hz}$, which is consistent with the data provided by other authors, e.g. Ladefoged \& Maddieson (1996) and Recasens \& Espinosa (2007).

Although rhotics are said to be susceptible to change, trills appear to be rather common sounds among them. In the UCLA Phonological Segment Inventory Database (UPSID), which includes information regarding the phonemic inventories of 451 languages, all of the world's languages that have a rhotic in their consonant inventory seem to have a trill, and an overwhelming majority of the trills (99.1\%) are produced in the alveolar/dental place of articulation (see also Maddieson 1984).

4. This phenomenon is referred to as the Bernoulli effect (Żygis 2005: 389). 


\subsection{The plain apical trill /r/}

As trilling crucially depends on the size and shape of the aperture as well as on the volume of airflow, minimal changes to one of the factors can result in a non-trilled realisation, i.e. either a fricative $[\mathrm{I}]$ or an approximant $[\mathrm{x}]$. The results of an experiment described in Solé (2002:672) strongly suggest that a pressure drop across the lingual constriction within the range of 2.5$3.5 \mathrm{~cm} \mathrm{H} 2 \mathrm{O}$ is sufficient to impair trilling (Figure 2). This finding may account for the sound's susceptibility to phonetic change as evidenced by synchronic and diachronic alterations of $[\mathrm{r}]$ to $[\mathrm{I}]$ or $[\mathrm{I}]$ that have been attested in many languages that have a trill in the inventory (Blecua 2001; Colantoni 2005; Wiese 2003; Verstraeten \& van de Velde 2001; Solé 2002; Recasens \& Espinosa 2007; Żygis 2005; Jaworski \& Gillian 2011).

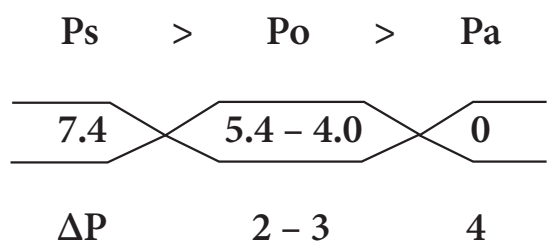

Figure 2. Values of subglottal pressure (Ps), oropharyngeal pressure (Po) and atmospheric pressure $(\mathrm{Pa})$, expressed in $\mathrm{cm} \mathrm{H} 2 \mathrm{O}$, across the lingual constriction required for trilling and voicing. The $\triangle \mathrm{P}$ parameter indicates the minimal pressure difference at the glottal and lingual constrictions (after Solé 2002: 675).

As noted above, due to their complexity, trills may pose a challenge to speakers and, therefore, may exhibit a considerable amount of variation. In the Slavonic languages, the articulatory variants of $/ \mathrm{r} /$ can be assigned to five phonetic categories that correspond to the following manners of articulation: trill, tap, fricative, approximant and affricate (Jaworski 2018). The number of allophones could be further extended by including the voiceless variants of trills, fricatives and affricates that occur regularly in certain contexts, e.g. word-finally. A voiceless trill is sometimes heard in Polish words such as teatr 'theatre' pronounced [tcatr]. However, in the same word, the final rhotic can also be realised as a fricative [teat $\mathrm{I}$ ] or, less frequently, an affricate [tzat八'] (see Jaworski 2018).

As for trilled allophones, they could be further divided into three subcategories, namely fully voiced, fricativised and approximantised trills. The main criterion for distinguishing the three types of trills is the degree of constriction produced by the articulating part of the tongue, which can be referred to as (i) complete closure, (ii) close approximation and (iii) open approximation. 
Fully articulated trills involve at least two constrictions of type (i). Fully voiced trills are composed of an alternating sequence of intermittent closures and vocalic elements, which makes them similar to a series of taps. A typical voiced trill, produced in the word раскаялся [ras'kajəłsə] 'he repented', is presented in Figure 3. It consists of three occlusions, the last of which has the form of an approximant. The three constrictions last 19, 21 and $22 \mathrm{~ms}$ respectively, while the vocalic intervals between them are slightly longer (23 and $24 \mathrm{~ms}$ ). The vocalic intervals have a distinct formant structure that indicates that the vocalic elements can be classified as mid-high central vowels. The values of F1 measured at midpoint are almost identical ( $428 \mathrm{~Hz}$ and $431 \mathrm{~Hz}$ ), and so are those of the second formant (1509 $\mathrm{Hz}$ and $1516 \mathrm{~Hz}$ ).

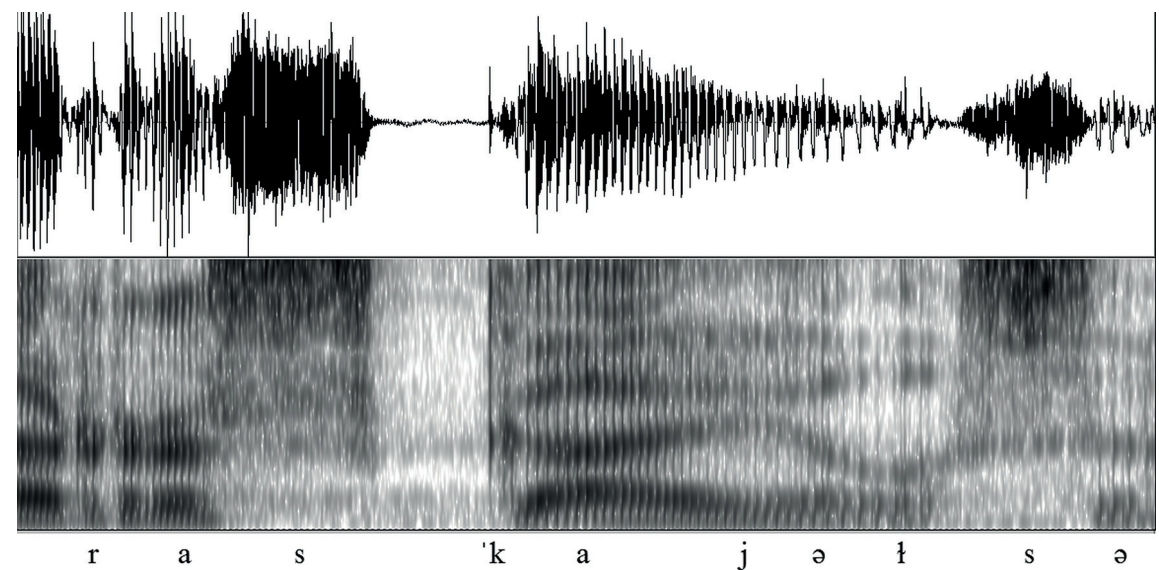

Figure 3. A trilled variant of Russian/r/ pronounced in the word раскаялся 'he repented'.

Fricativised trills differ from fully voiced trills in that a constriction of type (ii) is created between the alveolar ridge and the approximating apex. This rising gesture of the apex is termed close approximation by virtue of impeding the airflow to the extent that aperiodic noise is produced by the jet of air passing through the constriction. The auditory impression of trilling is thus made by an alternating sequence of periods of frication and vocalic elements. An initial fricativised trill, produced in the Ukrainian word руки [ru'ci] 'hand' (gen. sg.) in one of the audiobook recordings, is depicted in Figure 4. The characteristic feature of such tokens is that they consist of two usually incomplete constrictions separated by a period of aperiodic friction. The two constriction phases of 21 and 19 ms are almost complete, yet the 
intervening segment is by no means a vocalic element as it does not have any formant structure. The corresponding section of the waveform is composed of both periodic vibration and aperiodic friction; thus the element separating the constrictions should be classified as a voiced fricative element.

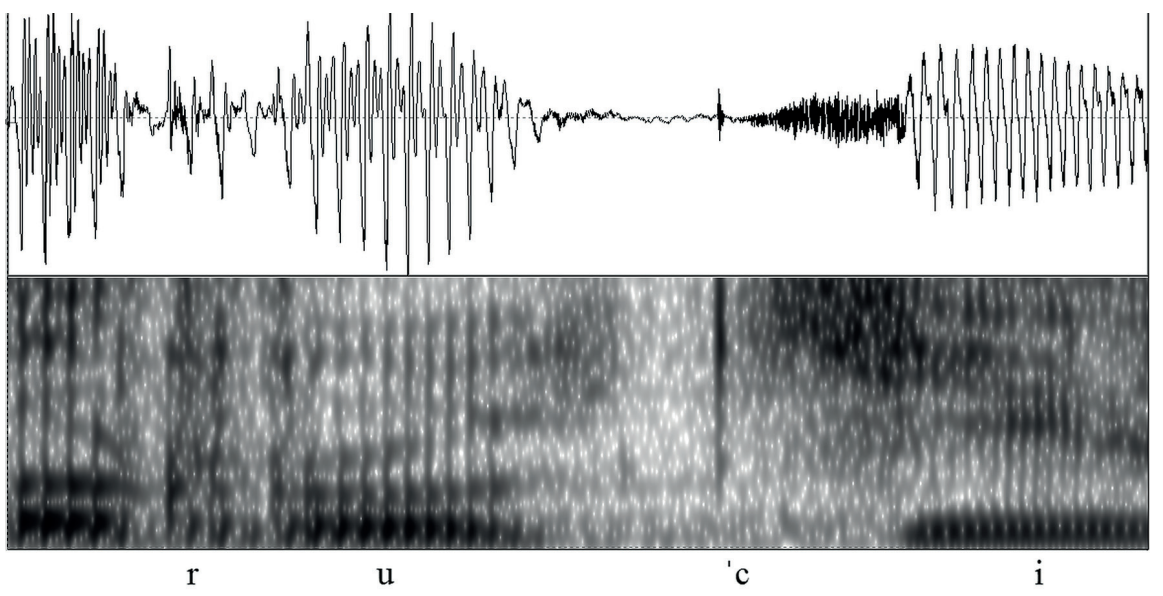

Figure 4. A fricativised trill produced in the Ukrainian word руки 'hand' (gen. sg.).

It is worth stressing that fricativised allophones represent a moderate degree of phonetic reduction. Further reduction of the apical gesture gives rise to approximantised allophones. An example of an initial approximantised trill, produced in the Belorussian word рыбаловы ' fishermen', is depicted in Figure 5. The sound consists of two incomplete constriction phases separated by a vocalic element. The intensity of the first constriction is noticeably lower than that of the following vocalic element. As for the other constriction, its phonetic properties hardly differ from those of the flanking vowels. However, the waveform shows that the amplitude of vibration drops when the approximant constrictions are produced, and it increases when the intervening vocalic element and the following vowel are articulated. It is these minute rising gestures of the apex that produce the auditory impression of trilling. 


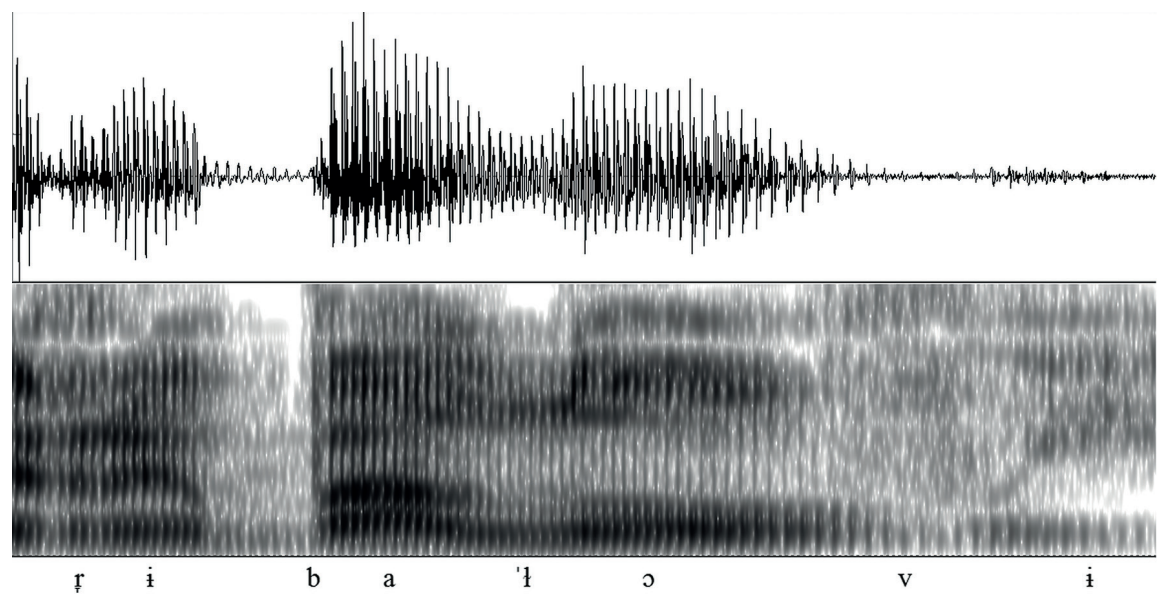

Figure 5. An approximantised trill produced in the Belorussian word рыбаловы 'fishermen'.

\subsection{Complex trills}

This section is concerned with complex trills, i.e. those in which trilling occurs simultaneously with an additional gesture. Although such features are usually referred to as secondary in the phonetic literature, ${ }^{5}$ the adjective additional is consistently used throughout the paper as the so-called secondary feature is sometimes preserved in various phonological contexts, whereas the primary one turns out to be redundant.

\subsubsection{Spirantised trill $/ \mathrm{r}_{0}^{\mathrm{h} /}$}

The spirantised trill $/ \mathrm{r}^{\mathrm{h}} /$, which is something of a rarity cross-linguistically, is found, for instance, in Welsh (Ball 2015). ${ }^{6}$ As suggested by the IPA symbol representing the sound, it can be thought of as an apical trill pronounced simultaneously with audible glottal friction. This sound $/ \mathrm{r}^{\mathrm{h}} /$ is represented by the digraph $<$ rh $>$ in Welsh orthography. The phonological status of the

5. Alternatively, such sounds may be referred to as marked trills Żygis (2005) argues that, in comparison with unmarked counterparts, marked segments are (i) less frequent in the world's languages (ii) more complex in terms of articulation, (iii) perceptually less salient, (iv) acquired later in the acquisition process, (v) phonetically unstable, and (vi) more narrowly distributed. These generalisations do not necessarily hold for all languages. For instance, in Welsh, whose grammar is based on a consonant mutation system that can be defined as "systematic morpheme-initial consonant alternations with a phonetically distinct consonant, not obviously caused by their phonetic and/or phonological context, but reflecting basic phonetic processes in the language, i.e. lenition, spirantisation and nasalisation" (Asmus and Grawunder 2017, fc.). Consequently, it is argued here that, in Welsh and Irish, a sound resulting from mutation cannot be regarded as marked.

6. The sound must be very infrequent indeed as the UCLA database does not list $/ \mathrm{r}^{\mathrm{h}} /$. 
segment arouses a certain degree of controversy. Jones (1984) maintains that both the plain apical trill $/ \mathrm{r} /$ and the spirantised apical $/ \mathrm{r}^{\mathrm{h}} /$ belong to the phonemic inventory of Modern Welsh. Two distinctive rhotic phonemes are also distinguished in Ball's (2015) analysis.

A carefully pronounced token of a spirantised trill, pronounced in the Welsh word rhwymo [r $\mathrm{r}^{\mathrm{h}} \mathrm{uj}$ 'mo] 'bind', is presented in Figure 6. On the spectrogram, the initial part of the sound in question is represented by a sequence of as many as seven closing gestures (the light vertical stripes) separated by periods of voicelessness. In this particular trill, the average duration of the incomplete closures is $8 \mathrm{~ms}$, while the mean duration of the periods of friction is $16 \mathrm{~ms}$. These temporal properties translate into the vibration rate of $43 \mathrm{~Hz}$. This rate is much higher than that obtained for voiced trills, which is on the order of $25 \mathrm{~Hz}$ (Lindau 1985; Ladefoged \& Maddieson 1996).
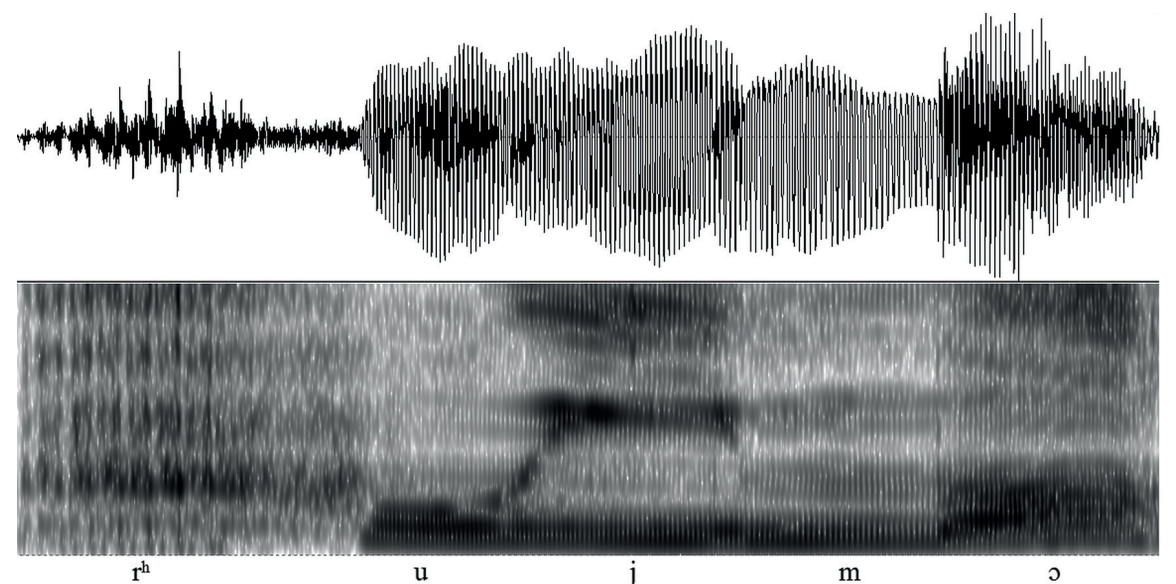

Figure 6. A carefully pronounced token of the spirantised trill of Welsh produced in the word rhywmo 'bind'.

Trills of this type certainly constitute an articulatory difficulty as gestures produced with different organs must be executed with perfect timing. In addition to that, throughout the sound, the critical difference between subglottal pressure and oropharyngeal pressure must be maintained to allow the repetitive movements of the apex to be made (Solé 2002). This requirement, which calls for a great degree of articulatory precision, makes trills in general, and complex trill in particular, prone to phonetic change. 


\subsubsection{The palatalised trill of Slavonic languages}

The palatalised trill of Slavonic languages poses a challenge for the speaker. Recasens \& Pollarès (1999) explain that the articulatory difficulty involved in the pronunciation of $\left[\mathrm{r}^{\mathrm{j}}\right]$ stems from two antagonistic gestures that need to be made. When the plain trill is pronounced, the predorsum is lowered and retracted, whereas for $\left[\mathrm{r}^{\mathrm{j}}\right]$ it is raised and fronted (see also Ladefoged \& Maddieson 1996; Solé 2002). These movements change the internal configuration of the speech organs reducing the likelihood of creating the aerodynamic conditions necessary for trilling. Consequently, the sound seems to be more prone to reduction than its plain counterpart.

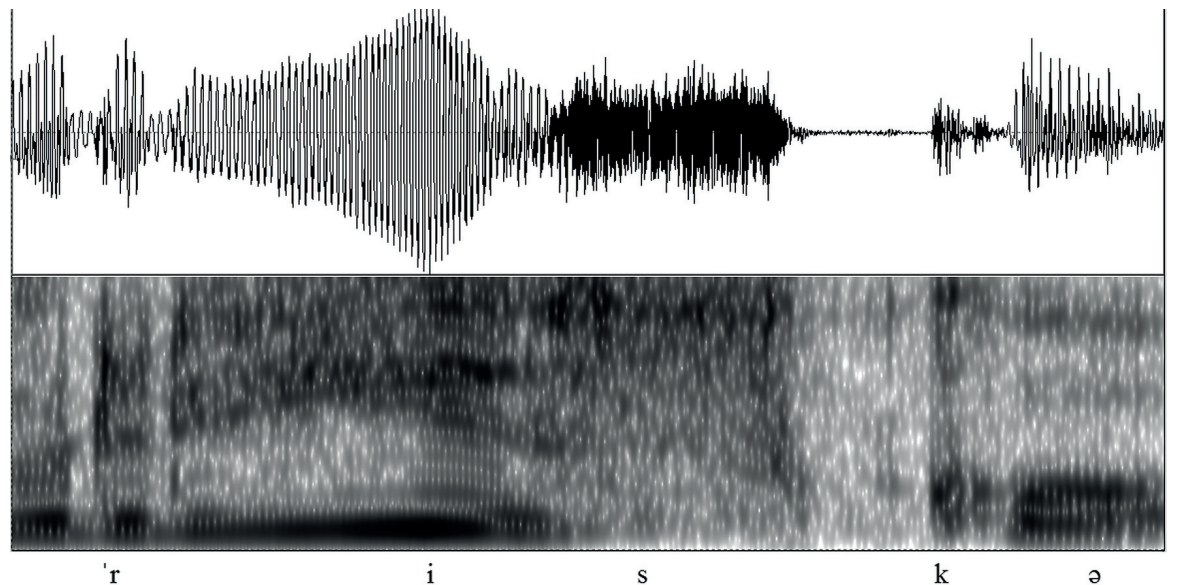

Figure 7. A trilled variant of the Ukrainian $/ \mathrm{r}^{\mathrm{j}} /$ produced in the word різко 'sharply'.

As regards the acoustic properties of $\left[\mathrm{r}^{\mathrm{j}}\right]$, they typically consist of two closures separated by a vocalic element. A representative example of a fully voiced trill, produced in the word різко ['riskə] 'sharply', is presented in Figure 7. This particular token consists of two taps and a vocalic element. ${ }^{7}$ The duration of the first tap is $18 \mathrm{~ms}$, whereas the other is $2 \mathrm{~ms}$ shorter. The separating vocalic element is $20 \mathrm{~ms}$ long. One full cycle of vibration lasts approximately $38 \mathrm{~ms}$, which translates into a vibration rate of $26.3 \mathrm{~Hz}$. The values of the formants of the vocalic element measured at mid point are $460 \mathrm{~Hz}$ and $2040 \mathrm{~Hz}$ for F1 and F2, respectively. Judging from these acoustic parameters, the vocoid should be labelled as a mid high front vowel.

7. As shown by the spectrogram, the vowel following the second constriction contains a substantial amount of friction that also results from the raised position of the dorsum. 
However, this finding is hardly surprising given that the trill is pronounced with the dorsum held close to the palate.

Predictably, trilled allophones of $/ \mathrm{r}^{\mathrm{j}} /$ constitute a minority variant in connected speech. Instead, speakers pronounce either fricatives or approximants. Interestingly, tapped variants of the phoneme are not as frequent as one might have expected (see Section 4 for details).

\subsubsection{The fricated trill of Czech}

The articulation of the phoneme $/ \mathrm{r} /$ appears to be highly idiosynchratic as different researchers provide divergent descriptions of the segment. According to Dankovičová (1999:71), the sound "starts as a trill and continues as a fricative". The author claims that it usually involves a greater number of vibrations than in the case of /r/. By contrast, Šimáčková et al. (2012:226) describe the fricated trill $/ \mathrm{r} /$ as "a period of friction interrupted at the beginning by a contact or contacts created by a retracted apico-alveolar gesture". The friction component of $/ \mathrm{r} /$ appears to be more distinct than trilling as foreigners normally perceive the rhotic as the post-alveolar fricative [3]. Howson et al. (2015:125) explain that this auditory impression is due to the shape of the opening for the trill. More specifically, the acoustic effect is produced by the wide flat channel that is created when the apex is not making contact with the palate, which bears a close resemblance to the tongue configuration for [ $\left.\int\right]$ and [3].

Figure 8 shows a fricated trill produced by a native speaker of Czech in the word $r$ rekl [rekl] 'he said'. The spectrogram shows clearly that the informant managed to produce one complete closure $(16 \mathrm{~ms})$ that was followed by a period of friction in the mid and high frequencies that lasted $43 \mathrm{~ms}$. This realisation is thus consistent with the account provided by Šimáčková et al. (2012). Judging from its acoustic properties, this token can hardly be labelled as a trill. By virtue of its acoustic properties, it should rather be called an affricated rhotic. Rhotics of the type presented in Figure 7 probably represent the most frequent allophone of $/ \mathrm{r} /$, but by no means should it be assumed that trilled variants no longer occur in the Czech language. In all likelihood, they are still produced in emphatic speech, declamatory styles and emotionally charged words. However, in wordinitial position, the sound tends to be reduced to a voiced fricative that can be represented by the symbol [x]]. 


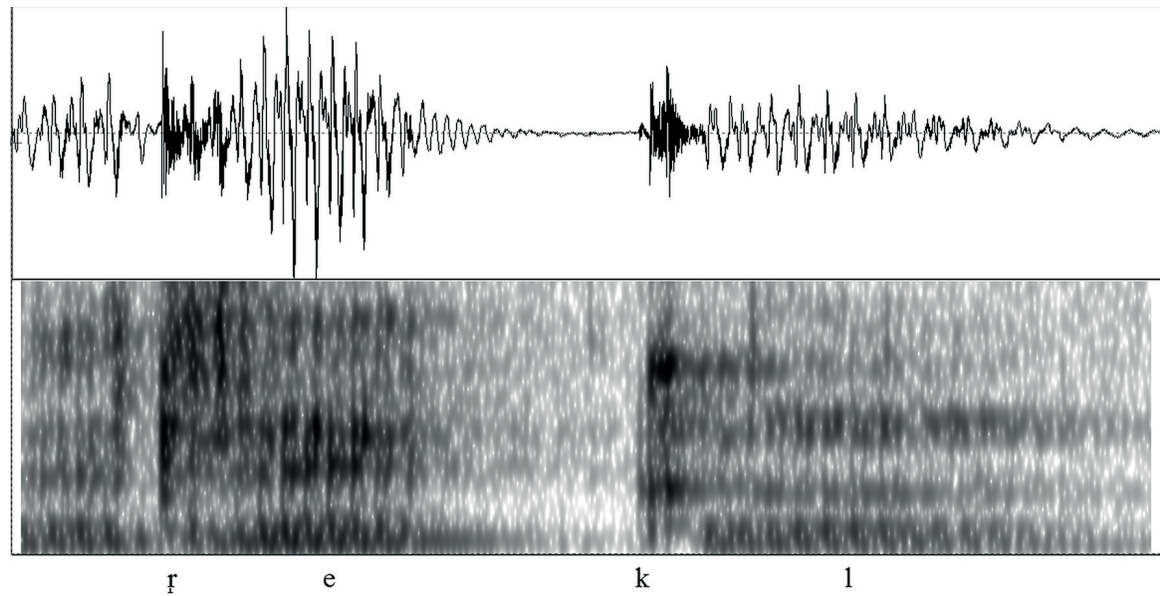

Figure 8. Fricated trill in the Czech word řekl [rekl] 'he said'.

\section{The study}

The objectives of the current study are fourfold: (i) to describe the acoustic properties of the spirantised rhotic of Welsh, (ii) to determine the range of allophonic variation of $/ \mathrm{r}^{\mathrm{h}} /$ by specifying which sounds are substituted or $/ \mathrm{r}^{\mathrm{h}} /$ in speech, (iii) to establish whether speakers coming from the South and the North of Wales produce the same allophones of $/ \mathrm{r}^{\mathrm{h}} /$ and (iv) to ascertain whether the spirantised trill $/ \mathrm{r}^{\mathrm{h}} /$ of Welsh, the palatalised $/ \mathrm{r}^{\mathrm{j}} /$ of Russian and Ukrainian, and the fricated $/ \mathrm{r} /$ of Czech exhibit a similar amount of variation. ${ }^{8}$

\subsection{The participants and data collection methods}

In order to achieve the goals of the study, different methods of data collection were used. In the case of Welsh, 23 native speakers of the language participated in the experiment. There is a considerable difference between representatives of the northern variety of Welsh and those who speak the southern dialect of the language. The informants were asked to read a list composed of 16 target words, embedded in the carrier phrase $D w i$ heb ddweud $\mathrm{X}$, ond $\mathrm{Y}$ !, which translates into English as 'I didn't say X, but Y!'. 9 The list was read twice so that each item occurred in the $\mathrm{X}$ and $\mathrm{Y}$ slots. ${ }^{10}$

8. It should be borne in mind that, in the Wels language, the sound $\left[r^{\mathrm{h}}\right]$ is an allophone of $/ \mathrm{r} /$, but it is not investigated in this study.

9. Literally, 'I am without say(ing) X, but Y'.

10. The second author prepared the wordlist, Sven Grawunder designed the experiment, while the acoustic analyses were conducted by the first author. 
Altogether, the participants produced 736 tokens of $/ \mathrm{r}^{\mathrm{h}} /, 7$ of which had to be excluded from analysis for technical reasons. The recordings were made in Szczecin, Poland, in 2014 and Leipzig, Germany, in 2014/2015. ${ }^{11}$ The Praat software (version 4.2.21) was used to make the recordings, digitise the data and produce the spectrograms and oscillograms.

As for the Slavonic languages, audiobook recordings of the Old Testament were used to obtain material for analysis. The acoustic properties of one hundred tokens of $/ \mathrm{r}^{\mathrm{j}} /$ pronounced by two native speakers of Russian and Ukrainian and the same number of tokens of $/ \mathrm{r} /$ pronounced by two Czech speakers were examined for the purposes of the paper. Since audiobooks are sold commercially, an assumption is made that the analysed speech samples represents the standard variety of the languages in question.

The two methods of data collection differed significantly, yet they also have certain things in common. First of all, in the four languages in question (Welsh, Russian, Ukrainian and Czech), samples of read speech were analysed. Also, only word or morpheme-initial rhotics were taken into consideration as the distribution of the Welsh spirantised rhotic is restricted to a greater extent than that of the Slavonic complex rhotics $/ \mathrm{r}^{\mathrm{j}} /$ and $/ \mathrm{r} / \mathrm{presen-}$ ted in sections 3.2.2 and 3.2.3. However, there is a considerable difference regarding the number of lexical items in which the rhotics occur. In the case of Welsh, there is a great disproportion between the numbers of informants speaking the northern and southern dialects, 19 and 4 respectively, yet the numbers of rhotics are sufficiently high to conduct a statistical analysis.

\subsection{Results and discussion}

The acoustic analysis of the data revealed that the Welsh spirantised rhotic may undergo radical phonetic reduction. In the examined speech samples, three allophones of the phoneme $/ \mathrm{r}^{\mathrm{h}} /$ can be distinguished. They differ with respect to the manner of articulation and were assigned to the following phonetic categories: trill, tap and fricative. The analysis also indicates that when $/ \mathrm{r}^{\mathrm{h}} /$ is realised phonetically as a spirant (or fricative), the resultant sound may be either a sibilant or a non-sibilant fricative. The major acoustic feature of the former is aperiodic noise of high intensity with a distinct lower cut-off frequency. The cross-linguistic analysis of spirants reveals that this frequency is higher, the more anterior the place of articulation of a fricative is

11. For participation we would like to thank Aled, Andrew, Bryn, Catrin, Delyth, Dewi, Eiri, Fflur, Guto, Gwyer, Hywel, Ifan, Judith, Lowri, Lois, Marian, Nia, Peredur, Rhiannon, Rhys and Eleri. For technical assistance, we also express our gratitude to Swen Grawunder, University of Kiel, Germany and Max Planck Institute for Evolutionary Anthropology, Leipzig, Germany. 
(Ladefoged \& Maddieson 1996: 163). In the case of non-sibilant fricatives, weak noise is present across the whole range of frequencies. This criterion is used in this study to classify allophones of $/ \mathrm{r}^{\mathrm{h}} /$ that were pronounced as fricatives.

The $/ \mathrm{r}^{\mathrm{h}} /$ pronounced as a sibilant fricative, in the word rhaff 'rope', is depicted in Figure 9. The major reason for selecting this item is that it allows the reader to compare the acoustic features of sibilant and non-sibilant fricatives pronounced within one word. The spectrogram shows clearly that the rhotic segment does not include any closures. Instead, it consists of a period of high-intensity friction that lasts $158 \mathrm{~ms}$ with a distinct cut-off point in the spectrum at, approximately, $2500 \mathrm{~Hz}$. Judging from its acoustic properties, the resultant fricative could be classified as a sibilant with a post-alveolar place of articulation. In other words, it has a quality similar to that of the [ $\left[\int\right]$ sound of English. Another piece of evidence as to the sibilant status of the spirantised $/ \mathrm{r}^{\mathrm{h}} /$ is provided by the oscillogram, which shows clearly that the amplitude of changes in air pressure produced by the sibilant is twice as high as that of the word-final [f].

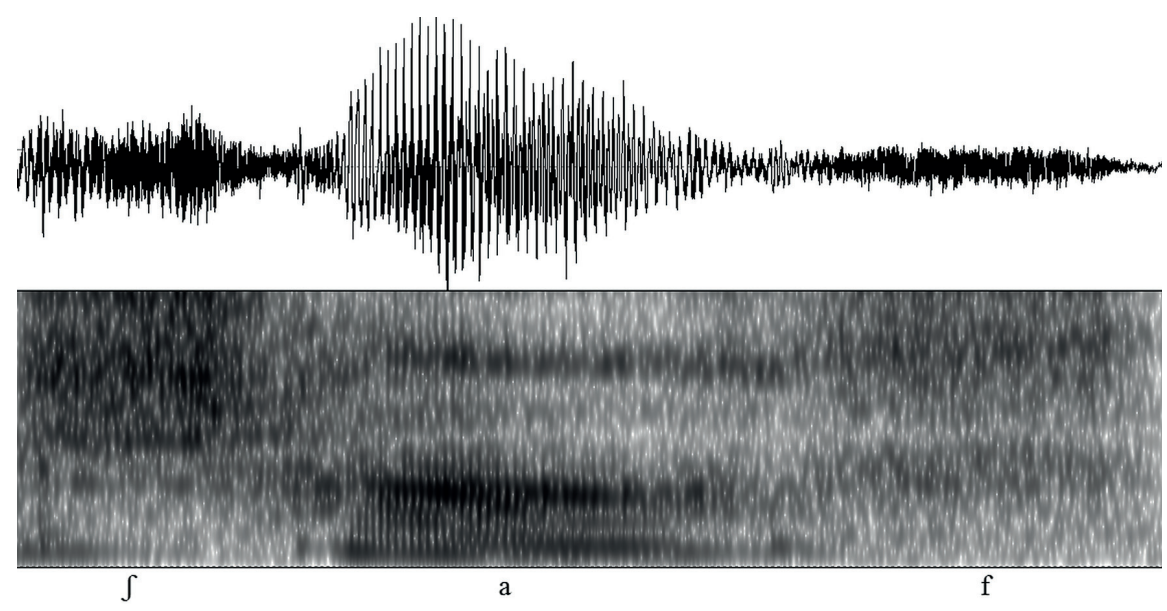

Figure 9. Spirantised rhotic of Welsh realised as a sibilant fricative in the word rhaff'rope'.

Non-sibilant realisations of the rhotic $/ \mathrm{r}^{\mathrm{h}} /$ have acoustic properties similar to those of [f]. As depicted in Figure 10, which includes a spectrogram of the word rhaff'rope' produced by a different speaker, the aperiodic noise of considerable duration (149 ms) extends across the whole frequency range, i.e. from $0 \mathrm{~Hz}$ to $5000 \mathrm{~Hz}$. The intensity of friction increases steadily as the fricative approaches the onset of the vowel due to partial voicing of the 
fricative. Neither of the fricatives has a noticeable cut-off point, which is a characteristic feature of non-sibilants.
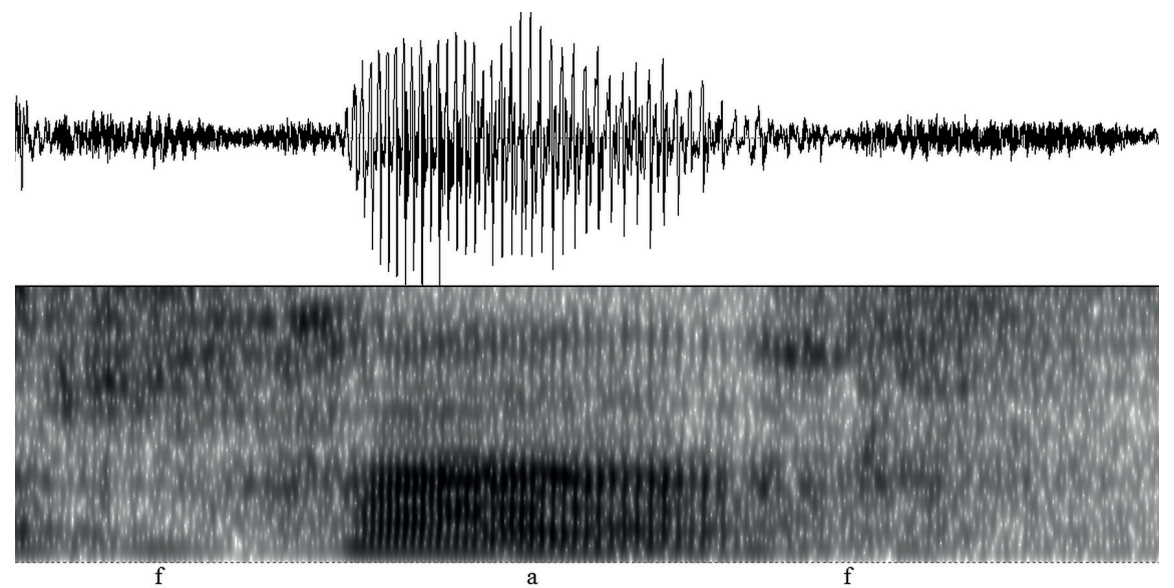

Figure 10. Spirantised rhotic of Welsh realised as a non-sibilant fricative in the word rhaff'rope'.

The examined recordings also include a number of interrupted realisations of $/ \mathrm{r}^{\mathrm{h}} /$ that cannot be called taps due to being made up of a closure phase followed by a relatively long period of friction. A representative allophone of this type, pronounced in the word rhan 'part', is presented in Figure 11. The 12-millisecond incomplete closure phase, represented by the light stripe in the spectrogram, is followed by a long period of friction (116 ms) occurring across the whole frequency range, which indicates that it is a non-sibilant fricative.

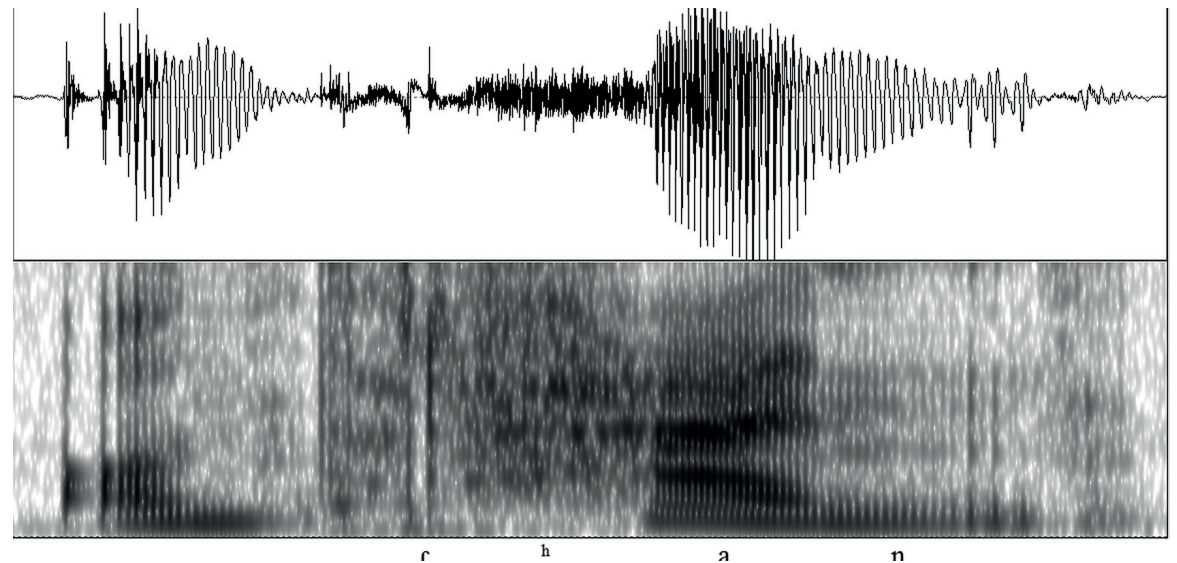

Figure 11. An interrupted realisation of $/ \mathrm{r}^{\mathrm{h}} /$ produced in the word rhan 'part'. 
The token in Figure 11 constitutes a taxonomic problem as it does not match any descriptions of tapped rhotics, nor can it be regarded as representing a trilled variant. Given its acoustic features, i.e. a closure followed by friction, one might argue that it could be referred to as an affricated rhotic. However, it is worth stressing that this realisation of $/ \mathrm{r}^{\mathrm{h}} /$ bears a striking resemblance to the allophone of the Czech fricated trill $/ \mathrm{r} /$ presented in Figure 8 above. Sounds having such characteristics are classified as trills in Czech despite having only one closure phase (see Šimáčková et al. 2012). ${ }^{12}$ Following this line of reasoning, trills made up of one closure represent a stage of reduction intermediate between trilled and fricativised variants. For lack of an appropriate label, throughout this work, they are tentatively referred to as one-tap trills and are represented by the symbol $\left[\mathrm{r}^{\mathrm{h}}\right]$ combining a tap and a non-sibilant fricative.

With respect to the palatalised trill $/ \mathrm{r}^{\mathrm{j}} /$ of Slavic, trilled variants of the sound are hardly ever produced. Although in some languages, e.g. Belorussian, the sound merged with its plain counterpart in all contexts, the phoneme tends to be realised as a fricative element in those languages that have it in their sound inventories. The same process affects $/ \mathrm{r} /$, but to a lesser extent (Jaworski 2018). Kasatkin (2006: 40) explains that:

При произнотении [p], [p'] контакт кончика языка с нёбом может иногда отсутствовать, чаще встречается это у [p']; в этом случае [p], [p'] могут реализоваться как щелевые согласные с тесной и короткой щелью. Наиболее характерна такая артикуляция [p'] в заударной интервокальной позиции и в конце слова: бе́рег, вари́ть, дверь, корь.

In the articulation of $[\mathrm{r}]$ and $\left[\mathrm{r}^{\mathrm{j}}\right]$, sometimes there can be no contact between the apex and the palate, more often in the case of $\left[\mathrm{r}^{\mathrm{j}}\right]$; in such cases, $[\mathrm{r}]$ and $\left[\mathrm{r}^{\mathrm{j}}\right]$ can be realised as fricatives with a narrow and short constriction. This type of articulation is most characteristic of $\left[\mathrm{r}^{\mathrm{j}}\right]$ in post-stress intervocalic position and at the end of the word, e.g. бépez 'shore', вapúmb 'to cook', дверь 'door', корь 'measles.'. ${ }^{13}$

Although this experiment is concerned with word-initial rhotics, it should be remembered that, in connected speech, rhotics preceded by a word-final vowel are, de facto, intervocalic. This makes them more susceptible to fricativisation, especially so if they constitute the onset segment of an unstressed syllable.

12. As a matter of fact, Ladefoged \& Maddieson (1996:245) use the phrase one-tap trill, but the authors do not explain how they differ from taps.

13. Translation by the author (S.J.). 

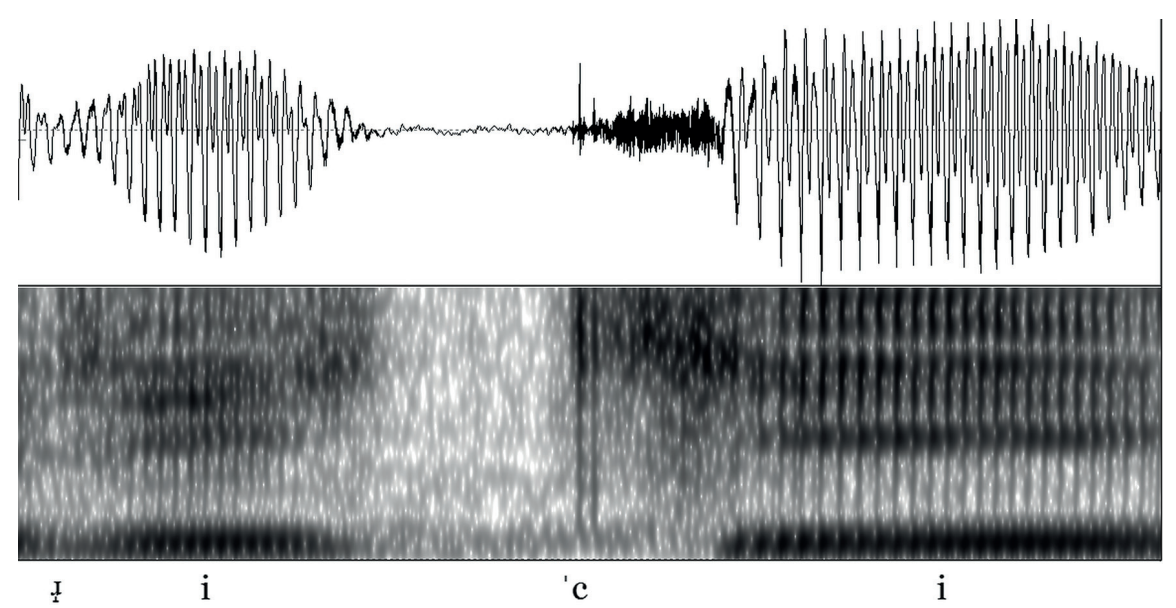

Figure 12. Fricativised allophone of the Russian phoneme $/ \mathrm{r}^{\mathrm{j}} /$ produced in the word реки 'river' (gen. sg.).

Figure 12 presents a word-initial token of $/ \mathrm{r}^{\mathrm{j}} /$, produced by a native speaker of Russian in the word реки [xi'ki] 'river' (gen. sg.), which illustrates the fricativisation process described in Kasatkin (2006). Both the spectrogram and the corresponding section of the oscillogram provide evidence that the friction component is superimposed on changes in air pressure caused by the movements of the vocal cords. This acoustic consequence of combining the two sources of energy is the lack of a distinct formant structure. The $/ \mathrm{r}^{\mathrm{j}} /$ phoneme can also be pronounced as an approximant if the constriction between the articulators is too wide for the jet of air to produce friction, but allophones of this type are rather rare in prosodically strong word-initial position.

An analysis of the acoustic properties of the three complex rhotics in question indicates that they differ with respect to allophonic variation observable in the examined recordings. As shown in (2), four articulatory variants of the Welsh spirantised rhotics were distinguished which include spirantised trills $\left[\mathrm{r}^{\mathrm{h}}\right]$, one-tap spirantised trills $\left[\mathrm{r}^{\mathrm{h}}\right]$, sibilant fricatives $[\mathrm{x} f]$ and non-sibilant fricatives [.xx]. ${ }^{14}$ As for the Czech fricated trill, all the examined tokens fall into either the one-tap trill $\left[\mathrm{r}^{\mathrm{h}}\right]$ or the fricative category $[\mathrm{x} 3]^{15}{ }^{15}$ The reason for using slightly different symbols to represent the

14. For lack of phonetic symbols representing natural classes of speech sound, [J] and [x] were selected arbitrarily to stand for sibilant and non-sibilant fricatives, respectively. By no means should it be understood that the trills are realised either as [J] or [x].

15. Dankovičová (1999) argues that the trill involves two or three closures, but such realisations were not encountered in the examined recordings. Therefore, this variant was bracketed to denote a possible, but unattested allophone. 
one-tap trills of Welsh and Czech is that they differ with respect to the feature [VOICE]. In our data, the Welsh sound is always [-VOICE], ${ }^{16}$ whereas the Czech segment is always [+VOICE], at least in this context. Finally, the palatalised rhotic of Russian and Ukrainian also has four major articulatory variants that are labeled as follows: palatalised trill [ $\left.\mathrm{r}^{\mathrm{j}}\right]$, palatalised tap $\left[\mathrm{r}^{\mathrm{j}}\right]$, palatalised ricativised rhotic $\left[\mathrm{I}_{1}^{\mathrm{j}}\right]$ and palatalised approximant $\left[\mathrm{x}^{\mathrm{j}}\right]$. The approximantised variants encountered in the East Slavonic languages represent the most radical form of reduction as they are vowel-like segments in terms of acoustic features.

(2)

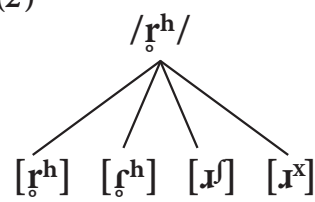

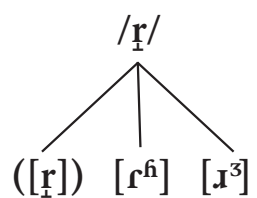

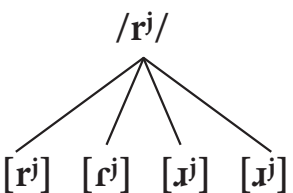

The allophones presented in (2) differ with respect to articulatory complexity, which definitely has an impact on their frequency of occurrence. Table 1 presents general statistical data regarding the distribution of the allophones in the four languages investigated in this study. The first conclusion that emerges from the analysis is that fricativised allophones, i.e. those that consist of a period of friction without any closure, constitute the majority variant in each language. ${ }^{17}$ By contrast, trilled variants that are supposed to be the articulatory target either do not occur in the recordings (in Czech), or their frequency of occurrence is unexpectedly low (in the case of Russian). In addition, voiced trills have more articulatory variants as fricativised allophones can be further reduced to approximants.

16. Asmus \& Grawunder (2017) argue convincingly that, in the case of the Insular Celtic languages, the opposition voiced-voiceless should rather be replaced with lenis-fortis.

17. In this work, the terms 'fricated trill' and 'fricativised trill' are introduced to distinguish two sounds of Czech. The former is used in the phonetic literature to refer to the Czech rhotic phoneme / $\mathrm{r}$ / that consists of trilling and friction produced simultaneously (see Dankovičová 1999). However, as shown in $t$ is study, the / $r /$ phoneme may have an allophone pronounced as a period of friction without a single closure phase. In this work, such allophones are referred to as fricativised trills, which seems to be a convenient phonetic label for the resultant sound. The same label is used to refer to those allophones of the spirantised $/ \mathrm{r}_{\circ}^{\mathrm{h}} /$ of Welsh and the palatalised $/ \mathrm{r}^{\mathrm{j}} /$ of Russian and Ukrainian that are realised phonetically as a period of friction. 
Table 1. Distribution of allophones of complex rhotics

$\begin{array}{lccccc}\text { Language } & \text { Tokens } & \text { Trill } & \begin{array}{c}\text { One-tap } \\ \text { trill/Tap }\end{array} & \text { Fricative } & \begin{array}{c}\text { Approx- } \\ \text { imant }\end{array} \\ \text { Welsh } & 729 & 92 & 31 & 606 & - \\ \text { Czech } & 100 & - & 24 & 76 & - \\ \text { Russian } & 100 & 4 & 18 & 63 & 15 \\ \text { Ukrainian } & 100 & 8 & 11 & 69 & 12\end{array}$

The spirantised trill of Welsh typically consists of two, less frequently three, incomplete closures separated by periods of friction. If two closures are produced, the duration of the constriction does not seem to be affected nor does the duration of the intervals of friction. The former is, on average, $8 \mathrm{~ms}$ long, whereas the mean duration of the latter is $15 \mathrm{~ms}$. Unfortunately, a reliable statistical comparison of the temporal characteristics of trilled variants pronounced by different speakers cannot be performed due to an insufficient number of tokens. The generalisations presented in this section are based on the performance of Speaker 6, a person with a trained voice, who herself articulated 21 trilled allophones of $/ \mathrm{r}^{\mathrm{h}} \%$

As regards the one-tapped allophone of the Welsh spirantised trill, its spectral characteristics, i.e. a closure phase followed by a period of friction, resemble the partially reduced allophone of the Czech trill. However, the two sounds differ considerably with respect to the temporal characteristics of both the closure phase and the friction. In Welsh, the closure phases range from $9 \mathrm{~ms}$ to $13 \mathrm{~ms}$, while in Czech the vary to a greater extent, i.e. from $11 \mathrm{~ms}$ to $18 \mathrm{~ms}$. On the other hand, the Welsh allophones have much longer periods of friction, which range between $73 \mathrm{~ms}$ and $139 \mathrm{~ms}$, while the period of friction is on the order of $50 \mathrm{~ms}$. By contrast, Russian and Ukrainian tapped variants are never followed by a period of friction. They consist of a single tap released into the following vowel. The mean duration of the closure phase is $16.8 \mathrm{~ms}$ in Russian and $17.1 \mathrm{~ms}$ in Ukrainian. Despite a relatively low number of tokens, a statistical test comparing the durations was performed and it yielded an insignificant result $(p=0.3185)$.

As for the fricativised allophones, there are three differences between Welsh and the three Slavonic languages. Fricativised variants are always fortis in Welsh, but never in the other languages, at least in word-initial position. 
In addition, Celtic and Slavic trills differ significantly in duration, with the Welsh language having the longest and the East Slavonic languages the shortest fricativised allophones. In Welsh, such sounds last up to $156 \mathrm{~ms}$, whereas in Czech their duration does not exceed 96 ms. By comparison, in Russian and Ukrainian, the period of friction can be as short as $25 \mathrm{~ms}$ and is hardly ever longer than $45 \mathrm{~ms}$.

In the case of the Welsh language, the informants were divided into northerners and southerners with a view to determining whether the allophones of $/ \mathrm{r}^{\mathrm{h}} /$ follow similar distribution patterns in their speech. However, the representatives of the north outnumber those of the south by the ratio of 19 to 4, which might have affected the final outcome of the experiment. Another dependent variable that was taken into consideration was the position occupied by the word within the sentence. The underlying assumption was that, in syntactically exposed position, i.e. following a pause, the rhotic $/ \mathrm{r}^{\mathrm{h}} /$ would be more resistant to phonetic change.

Table 2. Articulatory variants of $/ \mathrm{r}_{0}^{\mathrm{h}} /$ in stressed position (following a pause)

\begin{tabular}{lcccc} 
& \multicolumn{1}{c}{$\begin{array}{c}\text { NORTH } \\
\text { (19 speakers) }\end{array}$} & \multicolumn{2}{c}{$\begin{array}{c}\text { SOUTH } \\
\text { (4 speakers })\end{array}$} \\
& Tokens & $\%$ & Tokens & $\%$ \\
Trill & 72 & 23.7 & 5 & 7.8 \\
One-tap trill & 16 & 5.3 & 2 & 3.1 \\
$\begin{array}{l}\text { Fricativised } \\
\text { rhotic }\end{array}$ & 216 & 71.0 & & \\
\end{tabular}

Table 2 presents the articulatory variants of $/ \mathrm{r}^{\mathrm{h}} /$ produced by the informants in prosodically strong position. The two sets of data look similar in that fricativised allophones form a substantial majority, while one-tapped trills constitute the least frequent variant. In order to establish whether the allophones follow a similar distribution pattern, the data were compared statistically in a contingency table, which is a variant of the chi square test. The test did not confirm the initial impression as the differences between the two distribution patterns reached the level of significance $(F=9.1709 ; \mathrm{df}=2 ; p=0.0102)$. Nevertheless, the relatively high value of $p$ suggests that the result might have been different had the two groups been equal in number. 
The $/ \mathrm{r}^{\mathrm{h}} /$ sound was expected to be more susceptible to phonetic change when placed in unstressed, phrase-final position. As Table 3 shows, this assumption was confirmed, to a certain extent, as fewer trills and more fricativised allophones were produced by the northerners. As for the informants representing the south, there is hardly any change in comparison with the data presented in Table 2. The same statistical test performed on the data demonstrated that, in this context, the distribution patterns are almost identical $(F=0.1987 ; \mathrm{df}=2 ; p=0.9054)$. However, a highly significant difference was achieved when the patterns of distribution produced by the northerners in the stressed position were compared with those obtained in the unstressed position ( $\mathrm{F}=48.9304 ; \mathrm{df}=2 ; p=2.37 \mathrm{E}-11)$. In the case of speakers from the south, the distribution is very similar in both contexts $(F=1.2630 ; \mathrm{df}=2 ; p=0.5318)$.

\section{Table 3. Articulatory variants of $/ \mathrm{r}_{0}^{\mathrm{h}} /$ in stressed position (following a pause)}

\section{NORTH}

(19 speakers)
Tokens

Trill

One-tap trill

Fricativised rhotic
13

11

275
SOUTH

(4 speakers)

Having presented the results, it would be interesting to show how they relate to those of Thomas's (2000) Welsh Dialect Survey. It must be stressed, however, that the two studies differ significantly with regard to research methodology, methods of data analysis and, most of all, the recorded subjects. Therefore, certain differences seem to be inevitable.

The first noticeable discrepancy regards the number of allophones of $/ \mathrm{r}^{\mathrm{h}} /$, which is greater in Thomas (2000). For instance, according to the phonetic transcription, the word rhaff 'rope' as the following variants: [kra:f], [sa:f], [gra:f], [hra:f], [ra:f] (Thomas 2000: 98). Of these, only [sa:f], i.e. a fricativised variant with a sibilant, is attested in our study, where it is transcribed as [Ja:f] by virtue of the acoustic characteristics of the resultant fricative. None of the informants produced a deaspirated trill, as in [ra:f], nor did they pronounce a plosive-rhotic cluster as in [kra:f] or [gra:f]. Still, 
deaspiration appears to be the most frequent process applied Thomas' (2000) informants.

As for the frequency of occurrence of $\left[\mathrm{r}^{\mathrm{h}}\right]$ sounds, in Thomas (2000), approximately $50 \%$ of all tokens were classified as spirantised trills. By contrast, in the current investigation, only $21 \%$ of spirantised rhotics occurring in a prosodically strong position were trilled and as few as $4.2 \%$ of those that were found in an unstressed context at the end of a phrase were trilled. However, the results of both studies point out to the conclusion that the rhotic is less frequently trilled in the south of Wales than in the north.

\section{Conclusion}

Confirming Ball (2015) and Jones (1984), Welsh clearly has two distinct rhotic phonemes, although the spirantised one is rather unstable. The acoustic analysis conducted for the purposes of the study confirmed that the spirantised rhotic of Welsh exhibits a considerable amount of variation. Its allophones distinguished in this study include spirantised trills, one-tap trills, sibilant fricatives and non-sibilant fricatives. The obtained results also suggest that $/ \mathrm{r}^{\mathrm{h}} /$ may be undergoing a phonetic change. The claim is substantiated by the presented data, according to which fricativised allophones constitute the vast majority of the examined tokens not only in prosodically weak phrase-final position (92.2\%), but also in a syntactically exposed position (74.2\%). However, in order to identify the rhotic's potential for phonetic changes, a perception study would have to be undertaken.

Focusing on the spirantised rhotic, no attention was paid to possible variants of [r]. However, Asmus \& Grawunder (2017) show that [r] itself comes in two phonemes, i.e. lenis and fortis, so that Welsh seems to feature three distinct trills: lenis and fortis $/ \mathrm{r} /$ and fortis $/ \mathrm{r}^{\mathrm{h}} /$; these are probable remains of a development towards a fourfold sonorant system as found in Irish. This explains certain deviations of the Welsh spirantised trill which escapes various generalisations about trills and fricatives, e.g. their markedness. Nevertheless, as the Irish system is waning, a later perception study will show in which direction the spirantised trill may develop. So far, the trill seems to show more similarities in its potential change with the Slavonic languages, in which the palatalised and fricated trills tend to be fricativised, than with English. At least, no typical English /r/ phoneme could be identified as a replacement or $/ \mathrm{r}^{\mathrm{h}} \%$. The changes are shown graphically in Figure 13, which is a slightly modified version of the diagram presented in Figure 1. Our diagram includes the fricativisation as a possible stage of phonetic reduction affecting apical rhotics. The resultant sound, represented by the symbol $[\mathrm{I}]$, has been shown to constitute an allophone of the phoneme 
$/ \mathrm{r} /$ in the Slavonic languages (see Jaworski 2018). On the other hand, the evidence presented in this paper indicates that the spirantised rhotic of Welsh can also be rendered as a sibilant or non-sibilant fricative. The two allophones are represented in the graph by linking the Welsh rhotic $/ \mathrm{r}^{\mathrm{h}}$ / to both $[\mathrm{I}]$ and [z]. The rationale behind establishing the links is that the articulation of both $[\mathrm{I}]$ and $[\mathrm{z}]$ involve the front part of the tongue and the latter sound may result from retroflection (see Hamman 2003).

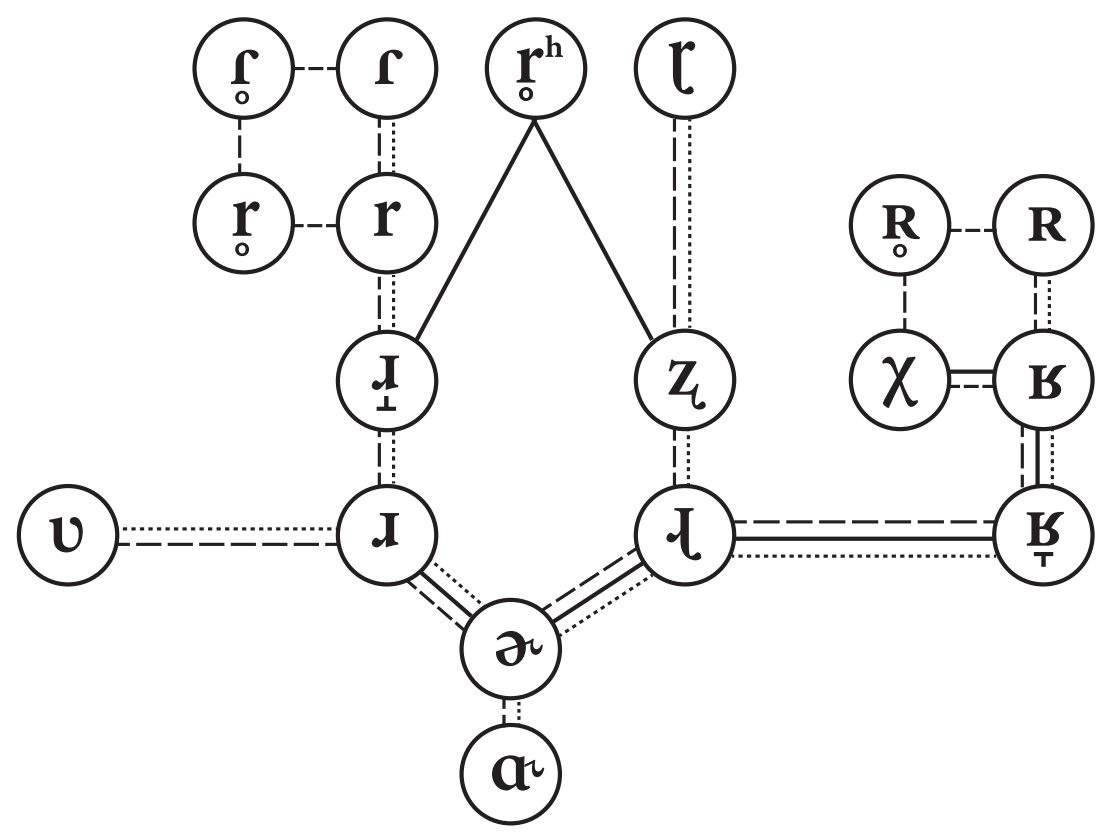

Figure 13. A modified version of Lindau's (1985) associations between various types of rhotics that includes the aspirated rhotic of Welsh.

With respect to pronunciation differences between speakers of the southern and northern dialects of Welsh, the results are rather inconclusive. Clearly, in order to clarify differences between northerners and southerners, further recordings need to be made, ideally with equal numbers of informants from both areas.

Sylwester Jaworski

University of Szczecin

Sabine Asmus University of Szczecin and University of Leipzig 


\section{References}

Asmus, S. \& Grawunder, S., 2017 (fc., working title), Vowel Length in Welsh Monosyllables, its Interrelation with Irish and Related Problems: An Acoustic Study and its Didactic Implications, Lewiston, 49-61.

Ball, M. J., 2015, 'How Many rhotic Phonemes does Modern Welsh Have', in: Czerniak, T, Czerniakowski, M. \& Jaskuła, K., eds., Representations and Interpretations in Celtic Studies, Lublin.

Blecua, B., 2001, Las vibrantes del Espanol: manifestaciones acusticas y procesos foneticos, unpublished $\mathrm{PhD}$ dissertation, Universidad Autonoma de Barcelona. Broderick, G., 2016, 'Hauptsprachliche Entwicklungen Im Britischen' (pc.). Carlton, L., 1990, Introduction to the Phonological History of the Slavic Languages, Columbus, $\mathrm{OH}$.

Colantoni, L., 2005, 'Increasing Periodicity to Reduce Similarity: An Acoustic Account of Deassibilation in Rhotics', in: Diaz-Campos, M., ed., Selected Proceedings of the 2nd Conference on Laboratory Approaches to Spanish Phonetics and Phonology, Somerville, MA, 22-34.

Dankovičová, J., 1999, 'Czech', Handbook of the International Phonetic Association: A Guide to the Use of the International Phonetic Alphabet, Cambridge, 70-74.

Demolin, D., 2001, 'Some Phonetic and Phonological Observations Concerning /R/ in Belgian French', in: Van de Velde, H \& van Hout, R., eds., R-atics: Sociolinguistic, Phonetic and Phonological Characteristics of / $r /$, Etudes and Travaux 4, Brussels, 63-74.

Gussmann, E., 2007, The Phonology of Polish, Oxford.

Hall, A. T., 1997, The Phonology of Coronals, Amsterdam \& Philadelphia.

Hamman, S., 2003, The Phonology of Retroflexes, Utrecht.

Hannahs, J. S., 2012, The Phonology of Welsh, Oxford.

Howson, Ph., Kochetov, A. \& van Lieshout, P., 2015, 'Elimination of the Grooving Patterns of the Czech Trill-fricative', Journal of Phonetics 49, 117-129. Hualde, J. I., 2005, The Sounds of Spanish, New York.

Jaworski, S., 2014, 'A Comparison of Croatian Syllabic [r] and Polish Obstruentised [r]', in: Witkoś, J. \& Jaworski, S., eds., New Insights into Slavic Linguistics, Frankfurt am Main, 179-192.

Jaworski, S., 2018, Rhotic Sounds in the Slavic languages: An Acoustic Study, Hamburg. Jaworski, S. \& Gillian, E., 2011, 'On the Phonetic Instability of the Polish Rhotic /r/', Poznań Studies in Contemporary Linguistics 47(2), 380-398.

Jones, G. E. , 1984, 'The Distinctive Vowels and Consonants of Welsh', in: Ball, M. J. \& Jones, G. E., eds., Welsh Phonology. Selected Readings, Cardiff.

Kasatkin, L. L., 2006, Sovriemiennij ruskij izik: fonietika [Modern Russian language: Phonetics], Moscow. 
Kavitskaya, D., Iskarous, K., Noiray, A. \& Proctor, M., 2009, 'Trills and Palatalisation: Consequences or Sound Change', in: Reich, J., Babyonyshev, M. \& Kavitskaya, D., eds., Proceedings of the Formal Approaches to Slavic Linguistics 17, Ann Arbor, 97-110.

Labov, W., 1966, The Social Stratification of English in New York City, Washington D.C.

Lindau, M , 1985, 'The Story of /r/', in: Fromkin, V. A., ed ., Phonetic Linguistics: Essays in Honor of Peter Ladefoged, New York, 157-168.

Ladefoged, P. \& Maddieson, I., 1996, The Sounds of the World's Languages, Chichester, West Sussex.

Lipski, J. M., 1987a, 'El español vestigial de Filipinas', Anuario de Lingüistica Hispanica (Valladolid) 3, 123-142.

Lipski, J. M., 1987 , 'Fonética fonología del español guineano’, Revista trimestral de cultura 2(1), 9-18.

Maddieson, I., 1984, Patterns of Sounds, Cambridge.

Recasens, D., \& Espinosa, A., 2007, 'Phonetic Typology and Positional Allophones or Alveolar Rhotics in Catalan', Phonetica 63, 1-28.

Recasens, D. \& Pallarès, M. D., 1999. 'A Study of $/ \mathrm{f} /$ and $/ \mathrm{r} /$ in the Light of 'DAC' Coarticulation Model', Journal of Phonetics 27, 143-169.

Rospond, S., 1973, Gramatyka historyczna jezzyka polskiego, Warszawa.

Solé, M-J., 2002, 'Aerodynamic Characteristics of Trills and Phonological Patterning', Journal of Phonetics 30, 655-688.

Šimáčková, Š., Podlipský, V. \& Chládková, K., 2012 'Czech Spoken in Bohemia and Moravia', Journal of the International Phonetic Association 42, 225-232.

Thomas, A. R., 2000, The Welsh Dialect Survey, Cardiff.

Walsh Dickey, L., 1997, The Phonology of Liquids, unpublished Ph.D. dissertation, University of Massachusetts, Amherst.

Verstraeten, B. \& van de Velde, H., 2001, 'Socio-Geographical Variation of /r/ in Standard Dutch', in: Van de Velde, H, and van Hout, R., eds., R-atics: Sociolinguistic, Phonetic and Phonological Characteristics of / $r$, Etudes and Travaux 4, Brussels, 45-62.

Vihman, M. M., 1996, Phonological Development. The Origins of Language in the Child, Oxford.

Wiese, R., 2003, 'The Unit and Variation of German /r/', Zeitschrift fur Dialektologie und Linguistik 70, 25-43.

Wiese, R ., 2011, 'The Representation of Rhotics', in: van Oostendorp, M., Ewen, C. J., Hume, E. \& Rice, K., eds., The Blackwell Companion to Phonology, Oxford, 711-729.

Żygis, M., 2005, '(Un)markedness of Trills: The Case of Slavic r-Palatalisation', Zeitschrift fur Slawistik 50, 383-407. 
Achevé d'imprimer sur les presses de Ouestélio

29200 Brest, en décembre 2018

\section{Dépôt légal}

